\title{
Visual Outcomes after Topography-Guided Femtosecond LASIK in Virgin Eyes
}

\author{
Ahmed Hassan Assaf, Sameh Hany Abd El Rahman, Mahmoud Abd El Meguid Abd El Latif, Mai \\ Mohammad Zaki Afifi \\ Ophthalmology Department, Faculty of Medicine, Ain Shams University \\ Corresponding author: Mai Mohammad Zaki Afifi, Email: drmai.m.zaki@ gmail.com
}

\begin{abstract}
Background: Laser vision correction has been established over the last 2 decades as a safe and effective intervention, with Laser-assisted in situ keratomileusis (LASIK), being one of the main techniques practiced globally. Femtosecond laser-assisted LASIK has become a popularized modification over the last decade and over the standard LASIK technique utilizing mechanical microkeratomes. A spherical ablation profiles performed by "wave front optimized" have been employed to reduce spherical aberration associated with myopic corrections.

Aim of the Work: To evaluate the quality and efficacy of topography-guided femtosecond lasik in virgin eyes with myopia, hypermetropia and astigmatism.

Patients and Methods: This comparative prospective study was conducted on 60 eyes of 30 Egyptian patients with comparing preoperative and postoperative outcomes. Eyes with myopia (-1.0 up to -8.0 diopters) or hypermetropia (+1.0 up to +5.0 diopters) or astigmatism (up to 5.0 diopters) or less. Eyes with central corneal thickness (CCT) of 500 microns or more. Eyes at risk for developing post-refractive corneal ectasia, such as keratoconus, keratoconus suspect, previous refractive surgery, corneal dystrophy, corneal guttae or opacities, any previous eye surgery e.g.:pseudophakic patients, retinal detachment surgery, all eyes were normal for example no cataract, no glaucoma, no retinal pathology and no previous trauma.

Results: Our study was performed on sixty eyes of thirty Egyptian patients. Sixty eyes of thirty patients underwent LASIK using T-CAT. Seventeen patients were females and thirteen were males. The average age of the patients was 24.8 year \pm 5.45 standard deviation (SD). The average spherical error was $-3.09 \mathrm{D} \pm 2.33 \mathrm{SD}$. The average cylinder error was $-1.02 \mathrm{D} \pm 1.02 \mathrm{SD}$.

Conclusion: The results showed that there was statistically significant differences between preoperative BCVA and postoperative UCVA with a good safety and efficiacy profile with T-CAT lasik as no patient loss even one line and $80 \%$ of cases gaining at least one line postoperative. The surgery was associated with higher values of high order aberrations after surgery than before surgery.
\end{abstract}

Keywords: Visual Outcomes, Guided Femtosecond LASIK, Virgin Eyes

\section{INTRODUCTION}

Laser vision correction has been established over the last 2 decades as a safe and effective intervention, with Laser-assisted in situ keratomileusis (LASIK), being one of the main techniques practiced globally ${ }^{(1,2)}$.

Femtosecond laser-assisted LASIK has become a popularized modification over the last decade and over the standard LASIK technique utilizing mechanical microkeratomes ${ }^{(3,4)}$.

Excimer lasers, used in the second step of a LASIK procedure to correct refractive error (RE), have been evolving as well, with most platforms currently utilizing flying spot technology of very high repetition rates and advanced tracking mechanisms to track intra-operatively the pupillary aperture and some even to provide cyclorotation adjustment ${ }^{(5,6)}$.

A spherical ablation profiles performed by "wave front optimized" have been employed to reduce spherical aberration associated with myopic corrections ${ }^{(7)}$.

Further customization of the ablation pattern has been practiced by pairing wave front eye data to the refractive data chosen to be corrected, as wave front-guided treatments in pursue of improving visual function in aberrated eyes, or pre-empting aberrations created by the standard procedures ${ }^{(8,9)}$.

Since most inherent and acquired eye aberrations lie in the cornea - the premiere refractive medium of the eye - topography-guided treatments have been additionally employed as a means of ablation customization in pursue of additionally correcting corneal irregularities affecting visual function ${ }^{(10)}$.

LASIK outcomes appear to have improved in safety and efficacy with the evolutions described earlier Zheng and Song ${ }^{(11)}$ in both refractive outcomes and induced high-order aberrations ${ }^{(12,13)}$. 
Further customization of the ablation pattern by utilizing topography data has been reported to provide excellent refractive data with regard to uncorrected visual acuity (UCVA) and best corrected visual acuity (BCVA) ${ }^{(10)}$.

\section{AIM OF THE WORK}

To evaluate the quality and efficacy of topography-guided femtosecond lasik in virgin eyes with myopia, hypermetropia and astigmatism.

\section{PATIENTS AND METHODS}

This comparative prospective study was conducted on 60 eyes of 30 Egyptian patients with comparing preoperative and postoperative outcomes. The study was approved by the Ethics Board of Ain Shams University.

\section{Patient Selection:}

Inclusion criteria: 1- Eyes with myopia (1.0 up to -8.0 diopters) or hypermetropia $(+1.0$ up to +5.0 diopters) or astigmatism (up to 5.0 diopters) or less. 2- Eyes with central corneal thickness (CCT) of 500 microns or more.

Exclusion criteria: 1- Eyes at risk for developing post-refractive corneal ectasia, such as keratoconus, keratoconus suspect. 2- Previous refractive surgery. 3- Corneal dystrophy, corneal guttae or opacities. 4-Any previous eye surgery e.g.:pseudophakic patients, retinal detachment surgery. 5- All eyes were normal for example no cataract, no glaucoma, no retinal pathology and no previous trauma.

Pre-Operative Examination: Complete ocular examination was done using the following: Autoreferaction. Visual Acuity Measurement: Uncorrected visual acuity (UCVA) and best corrected visual acuity (BCVA) decimal values. Contrast Sensitivity test by using CSV-1000E chart under photopic and mesopic conditions.

This test provides four (4) rows of sinewave gratings. At the recommended test distance of $8 \mathrm{ft}$ (2.5 meters), these gratings test the spatial frequencies of 3, 6, 12 and 18 cycles/degree (CPD). The CSV-1000E provides a full contrast sensitivity curve, which is very useful for the evaluation of contact lenses and refractive surgery, ocular disease (particularly cataracts, glaucoma, optic neuritis, diabetes and macular degeneration).

Topography Examination: The topeguided treatment was completely reliant on accurate and reliable topography examination data. For this reason, all topography examinations have been performed with great care. Only well-trained personnel could perform, validate and export examinations.

Operative steps: When preparing the patient for the treatment, attention was paid to the following points: ensure that the data on the laser matches the patient and eye was treated. Patient and eye data were shown on the laser LCD screen, pupil size for treatment during the topography examination. Medications likely to dilate the pupil were administered with careful supervision prior to surgery.

Statistical Analysis: Data were collected, revised, coded and entered to the Statistical Package for Social Science (IBM SPSS) version 23. The quantitative data were presented as mean, standard deviations and ranges when their distribution found parametric. Also qualitative data were presented as number and percentages.

\section{RESULTS}

Table (1): Comparison between preoperative BCVA and postoperative UCVA.

\begin{tabular}{|c|c|c|c|c|c|}
\hline & $\begin{array}{c}\text { Preoperative } \\
\text { (BCVA) }\end{array}$ & $\begin{array}{c}\text { Postoperative } \\
\text { (UCVA) }\end{array}$ & \multirow{2}{*}{$\begin{array}{c}\text { Test } \\
\text { value }\end{array}$} & \multirow{2}{*}{ P-value } \\
\hline & & No. $=\mathbf{3 0}$ & No. $=\mathbf{3 0}$ & & \\
\hline \begin{tabular}{|l|} 
Log MAR \\
VA
\end{tabular} & $\begin{array}{l}\text { Mean } \pm \text { SD } \\
\text { Range }\end{array}$ & $\begin{array}{c}0.003 \pm 0.018 \\
0-0.1\end{array}$ & $\begin{array}{c}-0.137 \pm 0.089 \\
-0.3-0\end{array}$ & 8.441 & 0.000 \\
\hline
\end{tabular}

Visual acuity was measured with decimal scale and converted to log MAR scale for statistical analysis. The mean postoperative UCVA was $0.137 \pm 0.089 \mathrm{SD}$ (range -0.3 to 0 ) compared to preoperative BCVA $0.003 \pm 0.018 \mathrm{SD}$ (range 0 to 0.1 ) with a highly statistically significant $p$-value.

Table (2): Comparison between preoperative and postoperative photopic contrast sensitivity.

\begin{tabular}{|c|c|c|c|c|c|}
\hline & Preoperative & Postoperative & \multirow{2}{*}{$\begin{array}{c}\text { Test } \\
\text { value }\end{array}$} & \multirow{2}{*}{ P-value } \\
\hline & & No. $=30$ & No. $=30$ & & \\
\hline $\begin{array}{l}\text { Photopic A } \\
\text { (3 cycles/ degree) }\end{array}$ & $\begin{array}{l}\text { Mean } \pm \text { SD } \\
\text { Range }\end{array}$ & $\begin{array}{c}6.67 \pm 0.92 \\
5-8\end{array}$ & $\begin{array}{c}7.33 \pm 0.80 \\
6-8\end{array}$ & -3.340 & 0.002 \\
\hline $\begin{array}{l}\text { Photopic B } \\
(6 \text { cycles/degree) }\end{array}$ & $\begin{array}{l}\text { Mean } \pm \text { SD } \\
\text { Range }\end{array}$ & $\begin{array}{c}6.27 \pm 0.98 \\
4-8\end{array}$ & $\begin{array}{c}7.23 \pm 0.86 \\
6-8\end{array}$ & -4.690 & 0.000 \\
\hline $\begin{array}{l}\text { Photopic } \mathrm{C} \\
\text { (12 cycles/degree) }\end{array}$ & $\begin{array}{l}\text { Mean } \pm \text { SD } \\
\text { Range }\end{array}$ & $\begin{array}{c}5.87 \pm 1.66 \\
2-8\end{array}$ & $\begin{array}{c}7.10 \pm 1.24 \\
4-8\end{array}$ & -3.892 & 0.001 \\
\hline $\begin{array}{l}\text { Photopic D } \\
(18 \text { cycles/degree })\end{array}$ & $\begin{array}{l}\text { Mean } \pm \text { SD } \\
\text { Range }\end{array}$ & $\begin{array}{c}5.20 \pm 1.88 \\
1-8\end{array}$ & $\begin{array}{c}6.50 \pm 1.28 \\
4-8\end{array}$ & -3.791 & 0.001 \\
\hline
\end{tabular}

The average preoperative photopic contrast sensitivity for low special frequency A (3 cycles/degree) was $6.67 \pm 0.92 \mathrm{SD}$ and $\mathrm{B}(6$ cycles/ 
degree) was $7.33 \pm 0.98 \mathrm{SD}$, While for high special frequency $\mathrm{C}$ (12 cycles/degree) was $5.87 \pm 1.66$ $\mathrm{SD}$ and D (18 cycles/ degree) was 5.20 $\pm 1.88 \mathrm{SD}$.

Table (3): Comparison between preoperative and postoperative mesopic contrast sensitivity.

\begin{tabular}{|c|c|c|c|c|c|}
\hline & Preoperative & Postoperative & \multirow{2}{*}{$\begin{array}{c}\text { Test } \\
\text { value }\end{array}$} & \multirow{2}{*}{ P-value } \\
\hline & & No. $=30$ & No. $=30$ & & \\
\hline $\begin{array}{l}\text { Mesopic A } \\
(3 \text { cycles/degree })\end{array}$ & $\begin{array}{l}\text { Mean } \pm \text { SD } \\
\text { Range }\end{array}$ & $\begin{array}{c}6.60 \pm 1.07 \\
5-8\end{array}$ & $\begin{array}{c}7.27 \pm 0.91 \\
6-8\end{array}$ & -2.660 & 0.013 \\
\hline $\begin{array}{l}\text { Mesopic B } \\
\text { (6 cycles/degree) }\end{array}$ & $\begin{array}{l}\text { Mean } \pm \text { SD } \\
\text { Range }\end{array}$ & $\begin{array}{c}6.50 \pm 1.20 \\
5-8\end{array}$ & $\begin{array}{c}7.07 \pm 0.78 \\
5-8\end{array}$ & -2.734 & 0.011 \\
\hline $\begin{array}{l}\text { Mesopic C } \\
(12 \text { cycles/degree) }\end{array}$ & $\begin{array}{l}\text { Mean } \pm \text { SD } \\
\text { Range }\end{array}$ & $\begin{array}{c}6.10 \pm 1.79 \\
2-8\end{array}$ & $\begin{array}{c}7.37 \pm 1.07 \\
5-8\end{array}$ & -3.856 & 0.001 \\
\hline $\begin{array}{l}\text { Mesopic D } \\
(18 \text { cycles/degree })\end{array}$ & $\begin{array}{l}\text { Mean } \pm \text { SD } \\
\text { Range }\end{array}$ & $\begin{array}{c}5.33 \pm 1.71 \\
1-8\end{array}$ & $\begin{array}{c}6.27 \pm 1.57 \\
4-8\end{array}$ & -2.580 & 0.015 \\
\hline
\end{tabular}

The average preoperative mesopic contrast sensitivity for special frequencies $3,6,12$ and 18 cycles/degree was $6.60 \pm 1.07 \mathrm{SD}, 6.50 \pm 1.20 \mathrm{SD}$, $6.10 \pm 1.79 \mathrm{SD}$ and $5.33 \pm 1.71 \mathrm{SD}$ respectively.

Table (4): Comparison between preoperative and postoperative spherical aberrations.

\begin{tabular}{|l|c|c|c|c|c|}
\hline \multicolumn{2}{|l|}{} & $\begin{array}{c}\text { Pre- } \\
\text { operative }\end{array}$ & $\begin{array}{c}\text { Post- } \\
\text { Operative }\end{array}$ & $\begin{array}{c}\text { Test } \\
\text { value }\end{array}$ & P-value \\
\cline { 3 - 5 } & No. = 60 & No. = 60 & & \\
\hline $\begin{array}{l}\text { Corneal spherical } \\
\text { aberrations }\end{array}$ & $\begin{array}{l}\text { Mean } \pm \text { SD } \\
\text { Range }\end{array}$ & $0.25 \pm 0.10$ & $0.32 \pm 0.26$ & -2.410 & 0.019 \\
\hline
\end{tabular}

The average preoperative corneal spherical aberrations was $0.25 \pm 0.10 \mathrm{SD}$ (range 0.06 to 0.41 ) compared to $0.32 \pm 0.26 \mathrm{SD}$ (range -0.5 to 0.69 ) postoperatively, $\mathrm{p}$-value $=0.019$ which is statistical significant.

\section{DISCUSSION}

LASIK surgery has advanced significantly in the past 2 decades. When it was first introduced, surgeons were able to reduce or eliminate patients' dependence on glasses or contact lenses. However, patients sometimes had to accept less than 20/20 uncorrected visual acuity (UCVA) and induced visual aberrations ${ }^{(14)}$.

One of the most interesting technical developments in laser refractive surgery during the last few years has been the emergence of the new ultrashort-pulse lasers (picosecond and femtosecond). Current clinical applications of femtosecond lasers have been developed to create flaps for LASIK ${ }^{(15)}$.

In contrast to LASIK flaps created with mechanical microkeratomes, the geometrically planar configuration of bladeless flaps has been suggested to confer advantages over microkeratome flaps, including the induction of fewer high-order aberrations and lesser astigmatism ${ }^{(16)}$.
TG procedure uses a proprietary topographyguided software system that maps the corneal surface of the eye for a customized correction plan for each patient, thereby creating a better quality of vision. The software delivers an improved accuracy of correction by combining the Vario (a device that measures the topography of the corneal surface at 22,000 measurement points) with the Wavelight EX500 and Topography-Guided Planning Software. The treatment planning software allowed for the creation of a unique surgical plan for each patient ${ }^{(14)}$.

TG treatments were once only used for treatment of irregular, pathological corneas. Early reports detailed successful corneal regularisation and improved vision following corneal trauma, keratoplasty, central islands and other laser ablation problems, such as decentred zones and small optic zones ${ }^{(17)}$.

While TG LASIK for irregular cornea continues to be of strong interest, reports of using these customised treatments in virgin eyes can also be found within the literature that demonstrate satisfactory outcomes overall ${ }^{(18,13)}$.

The main goal of this study was to evaluate the safety of topography-guided femtosecond lasik in virgin eyes with myopia, hypermetropia and astigmatism. This prospective study was conducted on 60 eyes of 30 Egyptian patients.

Sixty eyes of thirty patients underwent LASIK using T-CAT. Seventeen patients were females and thirteen were males. The mean age of the patients was 24.8 years $\pm 5.4 \mathrm{SD}$, The mean preoperative $\mathrm{SE}$ was $-3.09 \mathrm{D} \pm 2.33 \mathrm{SD}$ compared to $-0.27 \mathrm{D} \pm 0.39 \mathrm{SD}$ postoperatively and the mean preoperative cylinder error was $-1.02 \mathrm{D} \pm 1.02 \mathrm{SD}$ compared to $-0.54 \mathrm{D} \pm 0.24 \mathrm{SD}$ postoperatively.

The study showed statistically significant differences between preoperative BCVA and postoperative UCVA with a good safety and efficacy profile with T-CAT lasik as no patient loss even one line and $80 \%$ of cases gaining at least one line postoperative.

In a study done by Dougherty et al. ${ }^{(19)}$ They carried out a clinical trial enrolled 131 eyes, $116(88.55 \%)$ had an uncorrected visual acuity of $20 / 20$ or better and 122 (93.13\%), The best spectacle-corrected visual acuity (BCVA) increased by 2 or more lines in $21(16.03 \%)$ of 131 eyes; no eye lost 2 lines or more of BSCVA. 
Contrast sensitivity score resulted at 3 cycles/degree improved from an average preoperative value of 6.67 to 7.33 postoperatively, at 6 cycles/degree improved from an average preoperative value of 6.27 to 7.23 postoperatively, at 12 cycles/degree improved from an average preoperative value of 5.87 to 7.10 postoperatively, at 18 cycles/degree improved from an average preoperative value of 5.20 to 6.50 postoperatively.

In anothers study done by the same authors in 2016,they found an improvement in all special frequencies of 3-18 cycles/degree.

Corneal spherical aberration: In our study spherical aberrations increased significantly after surgery, the average preoperative corneal spherical aberrations was 0.25 ( range 0.06 to 0.41 ) compared to 0.32 (range 0.5 to 0.69 ) postoperatively, $p$-value $=0.019$ which is statistical significant, corneal coma aberrations: In our study corneal vertical coma aberrations significantly increased after surgery, the average preoperative vertical coma aberrations was -0.02 (range -0.42 to 0.3 ) compared to -0.11 (range -0.63 to 0.67 ) postoperatively, $\mathrm{p}$ value $=0.024$ which is statistical significant, while corneal horizontal coma aberrations non significantly increased, the average preoperative horizontal coma aberrations was -0.01 (range -0.33 to 0.52 ) compared to 0.02 (range -0.48 to 0.51 ) postoperatively, $\mathrm{p}$-value $=0.380$ which is not statistical significant, corneal trefoil aberrations: In our study corneal vertical trefoil aberrations significantly decreased after surgery, the average preoperative vertical trefoil aberrations was -0.10 (range -0.53 to 0.11 ) compared to -0.01 (range -0.22 to 0.24 ) postoperatively, $\mathrm{p}$-value $=0.000$ which is statistical significant.

While corneal horizontal trefoil aberrations none significantly decreased, the average preoperative horizontal coma aberrations was 0.01 (range -0.15 to 0.15 ), compared to -0.02 (range 0.30 to 0.30 ) postoperatively, $p$-value $=0.183$ which is not statistical significant.

Despite increasing of HOAs there was improvement of photopic and mesopic contrast sensitivity with fewer night driving and glare/halo symptoms postoperatively than preoperatively.

In a study undertaken by Dougherty $\boldsymbol{e t}$ al. (19) found that total ocular HOA increased by 0.04 microns. Patients reported significantly fewer night driving and glare/halo symptoms postoperatively than preoperatively.

In another study done by Shetty et al. ${ }^{(20)}$ found T-CAT ablation effectively achieved predictable refractive outcomes after myopic LASIK, with induction of fewer lower order aberrations and higher order aberrations.

In addition, Motwani ${ }^{(21)}$ found that Using WaveLight Contoura measured astigmatism and axis removes higher order aberrations and allows for the creation of a more uniform cornea with accurate removal of astigmatism, and reduction of aberration polynomials as polynomial analysis postoperatively showed that the average $\mathrm{C} 3$ was reduced by $86.5 \%$.

Our study was a single arm study and was unable to compare results with other modalities like WO and WG LASIK. There is controversy in the literature regarding the superior visual outcomes of the modalities. El Awady et al. ${ }^{(13)}$ and Jain et al. ${ }^{(22)}$ found superior BCVA postoperatively in the TG LASIK arm when compared to WO LASIK. However, Shetty et al. ${ }^{(20)}$ found no difference in this parameter. A comparable disparity is also seen when comparing the two custom ablation systems.

\section{CONCLUSION}

The results found in our study showed that there was statistically significant differences between preoperative BCVA and postoperative UCVA with a good safety and efficiacy profile with T-CAT lasik as no patient loss even one line and $80 \%$ of cases gaining at least one line postoperative. The surgery was associated with higher values of high order aberrations after surgery than before surgery. Compared to the preoperative status, we found a statistically significant increase of spherical and coma aberrations 3 months after T-CAT LASIK, although there was statistically significant improvement of photopic and mesopic contrast sensitivity with fewer night driving and glare/halo symptoms postoperatively than preoperatively. Further studies with larger numbers of cases and longer follow-up periods are needed to further evaluate changes in visual acuity and high order aberrations.

\section{REFERENCES}

1. Kugler LJ and Wang MX (2010): Lasers in refractive surgery: history, present, and future. Appl Opt., 49(25):1-9

2. Lukenda A, Martinović ZK and Kalauz $M$ (2012): Excimer laser correction of hyperopia, hyperopic and mixed astigmatism: past, present, and future. Acta Clin Croat., 51(2):299-304. 
3. Salomão MQ and Wilson SE (2010): Femtosecond laser in laser in situ keratomileusis. J Cataract Refract Surg., 36(6):1024-1032.

4. Reggiani-Mello G and Krueger RR (2011): Comparison of commercially available femtosecond lasers in refractive surgery. Expert Rev Opthalmol., 6(1):55-56.

5. Winkler MC, Khoramnia $R$ and Lohmann CP (2009): Comparison of different excimer laser ablation frequencies $(50,200$, and 500 Hz) Graefes Arch Clin Exp Ophthalmol., 247(11):1539-1545.

6. Alió JL, Vega-Estrada A, Arba Mosquera S and Moreno LJ (2012): Corneal higher order aberrations after LASIK for high myopia with a fast repetition rate excimer laser, optimized ablation profile, and femtosecond laser-assisted flap. J Refract Surg., 28(10):689-696.

7. De Ortueta, Magnago $\mathrm{T}$, Triefenbach $\mathrm{N}$, Arba Mosquera S, Sauer U and Brunsmann U (2012): In vivo measurements of thermal load during ablation in high-speed laser corneal refractive surgery. J Refract Surg., 28(1):53-58.

8. Aslanides IM, Kolli S, Padron S and Arba Mosquera S (2012): Stability of therapeutic retreatment of corneal wavefront customized ablation with the Schwind cam: 4-year data. J Refract Surg., 28(5):347-352.

9. Smadja D, Reggiani-Mello G, Santhiago MR and Krueger RR (2012): Wavefront ablation profiles in refractive surgery: description, results, and limitations. J Refract Surg., 28(3):224-232.

10. Kanellopoulos AJ (2016): Topographymodified refraction (TMR): adjustment of treated cylinder amount and axis to the topography versus standard clinical refraction in myopic topography-guided LASIK. Clin Ophthalmol., 10:2213-2221.

11. Zheng $H$ and Song LW (2011): Visual quality of Q-value-guided LASIK in the treatment of high myopia. Yan Ke Xue Bao., 26(4):208-210.

12. Alio JL, Vega-Estrada $A$ and Piñero DP (2011): Laser-assisted in situ keratomileusis in high levels of myopia with the amaris excimer laser using optimized aspherical profiles. Am J Ophthalmol., 152(6):954-963.
13. El Awady HE, Ghanem AA and Saleh SM (2011): Wavefront-optimized ablation versus topography-guided customized ablation in myopic LASIK: comparative study of higher order aberrations. Ophthalmic Surg Lasers Imaging, 42(4):314-320.

14. Stulting L (2014): Topography-guided LASIK: A paradigm shift in refractive laser treatment. Ophthalmology, 29: 250-254.

15. Kurtz RM, Horvath C and Liu HH (1998): Lamellar refractive surgery with scanned picoseconds and femtosecond laser pulses. J Refract Surg., 14:541-548.

16. Kerizian GM and Stonecipher KG (2004): Comparison of the IntraLase femtosecond laser and mechanical microkeratomes for laser in situ keratomileusis. J Cataract Refract Surg., 30:804-811.

17. Knorz MC and Jendritza B (2000): Topographically-guided laser in situ keratomileusis to treat corneal irregularities. Ophthalmology, 107:1138-1143.

18. Vinciguerra $P$, Camesasca $F$, Bains $H$, Trazza $S$ and Albè $E$ (2009): Photorefractive Keratectomy for Primary Myopia Using NIDEK Topography-guided Customized Aspheric Transition Zone J Refract Surg., 25: 89-92.

19. Dougherty PJ, Waring G, Chayet A, Fischer J, Fant B and Bains HS (2008): Topographically guided laser in situ keratomileusis for myopia using a customized aspherical treatment zone. $\mathrm{J}$ Cataract Refract Surg., 34:1862-1871.

20. Shetty R, Shroff R, Deshpande K, Gowda R, Lahane $S$ and Jayadev C (2017): A prospective study to compare visual outcomes between wavefront-optimized and topography-guided ablation profiles in contralateral eyes with myopia. J Cataract Refract Surg., 33:6-10.

21. Motwani M (2017): The use of WaveLight ${ }^{\circledR}$ Contoura to create a uniform cornea: the LYRA Protocol. Part 3: the results of 50 treated eyes. Clin Ophthalmol., 11:915-921.

22. Jain AK, Malhotra $C$, Pasari A, Kumar $P$ and Moshirfar M (2016): Outcomes of topographyguided versus wavefront-optimized laser in situ keratomileusis for myopia in virgin eyes. $\mathbf{J}$ Cataract Refract Surg., 42(9):1302-1311. 